\title{
Prevalence and characteristics of autistic children attending autism centres in 2 major cities in Saudi Arabia
}

\author{
A cross-sectional study
}

Heba J. Sabbagh, MDS, PhD, Basma A. Al-Jabri, MD, Malek A. Alsulami, BDS,

Lutfi A. Hashem, BDS, Ala A. Aljubour, BDS, MDS, Rana A. Alamoudi, $D S_{c} D, A B P D$.

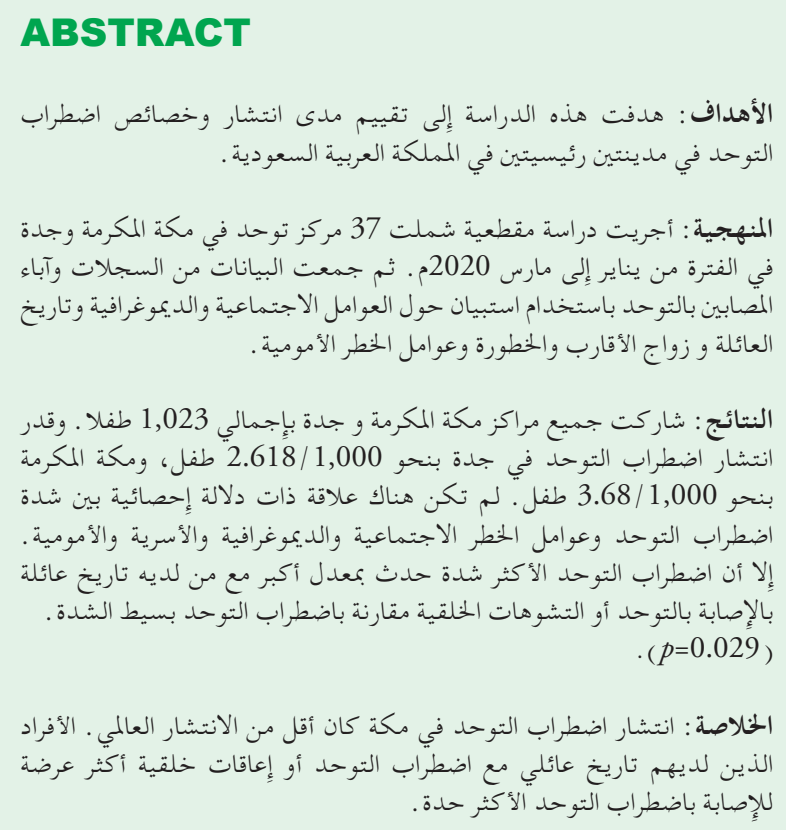

Objectives: To assess the prevalence and characteristics of Autism Spectrum Disorder (ASD)-affected children attending autistic centers in 2 major cities in Saudi Arabia.

Methods: A cross-sectional study, including ASD centers and schools (37 centers) in Makkah and Jeddah, Saudi Arabia was conducted between January and March 2020. Data were collected from records and parents of children with ASD using a questionnaire on sociodemographic, family history, consanguinity, severity, and maternal risk factors.

Results: All centers in Makkah and Jeddah participated, with a total of 1,023 ASD children. The prevalence of ASD was 2.618 per 1,000 children for Jeddah, 3.68 per 1,000 children for Makkah and 2.81 per 1,000 children for both Jeddah and Makkah. There was no statistically significant relationship between the severity of ASD and sociodemographic, family and maternal risk factors. However, there was statistically significant relationship between severe ASD and ASD family history ( $p=0.029$, OR: 3.46 and $95 \%$ CI 1.14 to 10.5 ).

Conclusions: The prevalence of ASD in Makkah and Jeddah was lower than the global prevalence of ASD. Individuals with a family history of ASD were more likely to have more severe ASD.

Keywords: autism spectrum disorder, autism, ASD, Saudi Arabia, determinants of autism, autism in Jeddah, autism in Makkah

Saudi Med J 2021; Vol. 42 (4): 419-427

doi: 10.15537/smj.2021.42.4.20200630

From the Department of Pediatric Dentistry (Sabbagh, Aljubour, Alamoudi), College of Dentistry (Alsulami, Hashem) and from the Department of Pediatrics (Al-Jabri), Faculty of Medicine, Jeddah, Kingdom of Saudi Arabia.

Received 18th October 2020. Accepted 22nd February 2021.

Address correspondence and reprintrequest to: Dr. HebaJ. Sabbagh, Assistant Professor, Department of Pediatric Dentistry, King Abdulaziz University, Jeddah, Kingdom of Saudi Arabia. E-mail: hsabbagh@kau.edu.sa ORCID ID: http://orcid.org/0000-0002-9788-0379

A utism spectrum disorder (ASD) is one of the most common neurodevelopmental disorders in the world. ${ }^{1}$ This disorder is characterized by persistent deficits in social communication and interaction, including language development, along with restricted repetitive patterns of behaviors, interests, and activities. $^{2}$ The exact etiology of ASD is unknown, but multiple studies have linked it to both genetic and environmental factors. Varcin et $\mathrm{al}^{3}$ investigated 
whether ASD is associated with exposure to stressful events during pregnancy. ${ }^{3}$ The study findings showed that the prevalence of ASD in Louisiana children had significantly increased following hurricanes and tropical storms exposure during the prenatal period. Children with ASD have a risk of developing different comorbid conditions such as learning difficulties, attention deficit, seizure disorder, and cognitive impairment. ${ }^{4}$

Experts throughout the world have been interested in the prevalence of ASD. Statistics from the World Health Organization indicate that the global prevalence of ASD is 6.25 per 1,000 population. ${ }^{5}$ A number of attempts have been made towards determining the prevalence of ASD in different countries. A systematic review featuring 27 studies conducted by Adak et $\mathrm{al}^{6}$ on the prevalence of ASD found that the average prevalence of ASD was 9.19 per 1,000 population; the prevalence of ASD varied substantially by country, gender, socioeconomic status, geographic region, continent, and the assessment tools used.

In the Kingdom of Saudi Arabia (KSA), a review conducted by Taha and Hussien ${ }^{7}$ revealed that the prevalence of ASD in the Arab countries was reported to be higher than that of other developing countries, with 42,500 confirmed cases in 2002 and likely many more undiagnosed cases. ${ }^{7}$ Research on the prevalence of ASD in different regions and cities within the KSA is limited; therefore, there is little understanding about the prevalence of ASD even in the country's major cities. Further, the association between different demographic, socioeconomic, and family history factors and ASD, its etiological factors, and severity remains unclear.

This study aimed to assess the prevalence of ASD children attending autistic centers in 2 major cities (Makkah and Jeddah) located in the western region of Saudi Arabia. In addition, it assessed the relationship between sociodemographic, child, maternal, and family factors and the severity of ASD among children in the western region of Saudi Arabia. The outcome of this research is expected to play a role in building the baseline for future studies on ASD children's health quality, and ASD etiology. Especially, that recent evidence has determined a change in the ASD prevalence. Therefore, the research had 2 questions: 1) What is the prevalence of ASD attending ASD educational centers in Jeddah and Makkah? and 2) Is there a relationship between

Disclosure. Authors have no conflict of interests, and the work was not supported or funded by any drug company. different environmental and family risk factors and ASD severity?

Methods. Once a child is diagnosed with ASD by medical personnel, she/he will be enrolled in a rehabilitation center for participation in interventional programs. Children in the rehabilitation ASD centers and those enrolled in a special ASD programs in regular schools under the Ministry of Education (MOE) in Saudi Arabia are regulated by the Ministry of Human Resources and Social Development (MHRSD). ${ }^{8}$ The MHRSD mandates that children with ASD must receive a diagnostic assessment by a specialized physician in a governmental hospital (namely, developmental pediatrician, child neurologist, or child psychiatrist). This assessment must state the diagnosis and the severity, along with any comorbid conditions. Copies of the medical assessment are available for the parents, the rehabilitation center as well as the MHRSD. The severity of the disorder, determined by the extent of the impairment in social communication and restricted behaviors and interests, is clinically diagnosed by a specialist physician following the classification in the Diagnostic and Statistical Manual of Mental Health Disorders (DSM-5) (APA 2013). ${ }^{9}$

This study followed a cross-sectional design including all rehabilitation centers and schools serving children diagnosed with ASD in Jeddah and Makkah cities. These cities are considered the second and third largest cities in the KSA (Saudi General Authority for Statistics). ${ }^{10}$ The study screened 37 specialist centers and ASD schools; 25 in Jeddah and 12 in Makkah registered by the $\mathrm{MHRSD}^{8}$ aiming to represent the majority of the autistic children in the region. The data were collected from January to March 2020.

To assess environmental and family related risk factors, ASD children from 16 centers distributed in Jeddah and Makkah were included in this study. The required sample size was calculated using an online calculator "Open Source Epidemiologic Statistics for Public Health online software (www.openepi.com)". The sample size was calculated based on the estimated prevalence of ASD family history among ASD children (15\%) reported by Hansen et $\mathrm{al}^{11}$ and the results of this study. The calculation indicated a sample size of 150 ASD children with a power level of $80 \%$, design effect of 3 for cluster sample, and a confidence level of $95 \% .{ }^{11}$

Inclusion criteria included Saudi children diagnosed with ASD, aged 6 to 12 years old, living in Makkah and Jeddah. Exclusion criteria included non-Saudi children, children not living in Makkah and Jeddah, or another age group (Figure 1). 
Data were collected from the records of the rehabilitation centers under the MHRSD and the MOE and from parents' responses to our questionnaire. The rehabilitation centers and schools provided information on the number of ASD children, their age and gender. This information was used to assess ASD prevalence. In addition, a questionnaire was sent to the parents to assess ASD risk factors. An informed consent form was sent to parents for their approval before the research began.

The Arabic, self-report questionnaire was constructed according to previous research assessing a congenital anomaly in Saudi Arabia and a systematic review on ASD etiology. ${ }^{12,13}$ The search was carried out by entering keywords following MeSh terms such as "autism", "prevalence", "aetiology", "risk factors" and "Saudi Arabia" in 3 search engines (PubMed, Scopus and Google Scholar) from 2000 to 2020.

The questionnaire was validated by 6 consultant pediatric dentists and developmental pediatricians for content validity (Item Content Validity Index [Item-CVI] $=1$ ) and by 20 parents for face validity. The data collection form was divided into 2 main parts: 1) children's demographic data, general information, and family socioeconomic status (SES); and 2) severity of ASD symptoms, along with possible risk factors including maternal, child, and family risk factors.
Ethical approval was obtained from the King Abdulaziz University Faculty of Dentistry's (KAUFD), Jeddah, KSA committee with reference number of 148-11-19. The participants provided informed consent before participating in the study. They were assured their participation was anonymous.

Statistical analysis. The prevalence of ASD children in Makkah and Jeddah attending educational centers were estimated in this study. We divided the total number of identified cases in the included centers by an estimated denominator. This denominator was calculated from 2 sources for assertion: 1) from the total number of children in the same age group in the selected city, according to the records of General Authority for Statistics in the Kingdom of Saudi Arabia for children attending schools that has the same age group of the included ASD children (total 1 is 317,273 child including 207,808 child from Jeddah and 109,465 child from Makkah); ${ }^{14}$ and 2) from the total number of children born between 2008 to 2014, including the ASD cases, according to the Ministry of Health's statistical book (total 2 is 376,800 child including 271,800 children from Jeddah and 105,000 children from Makkah). ${ }^{15}$ The average of these 2 figures ([Total $1+$ Total 2]/ 2 = 347,036 including 239,804 from Jeddah and 107,233 from Makkah) was used as the denominator.

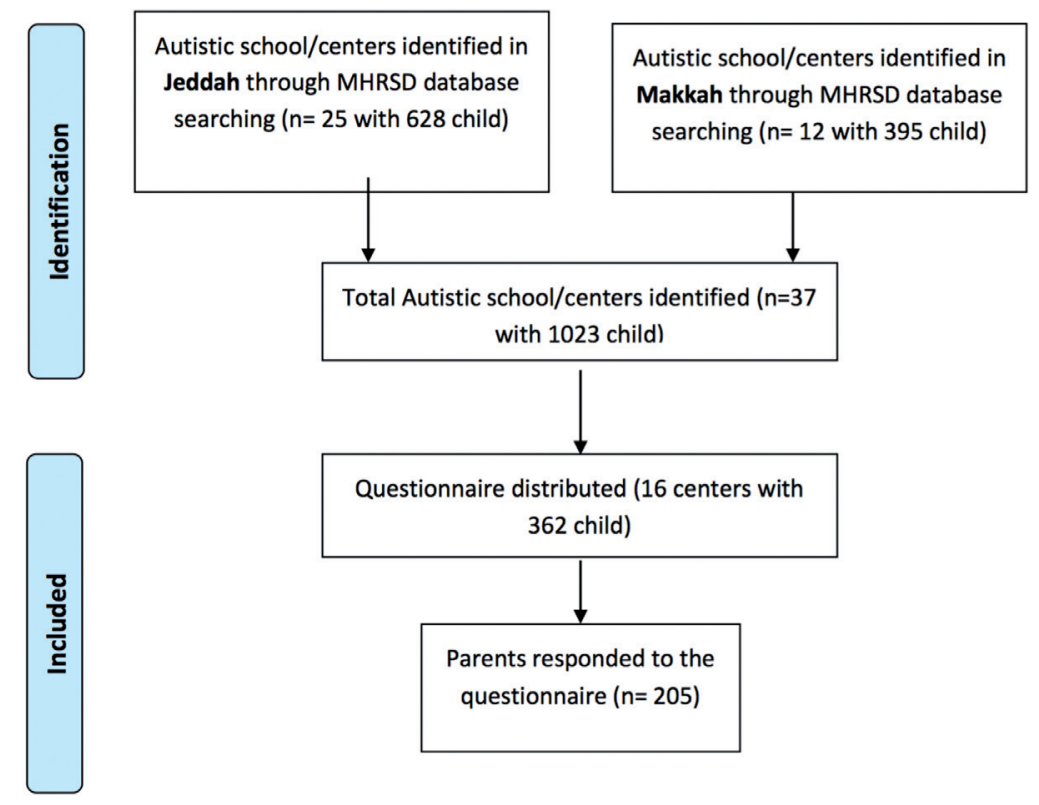

Figure 1 - Study Flow Diagram for included autistic centers/ schools and participants. MHRSD: Ministry of Human Resources and Social Developments 
In addition, data was entered into Statistical Package for Social Sciences (SPSS) version 16.0 (SPSS Inc., Chicago, IL, USA). Continuous variables were presented in terms of means, while categorical variables were presented in terms of frequencies and percentages and analyzed using Chi-square tests. Odds ratios (OR) and confidence intervals (CI) were used for categorical variables. The significance level was set at $p \leq 0.05$.

Results. A total of 37 centers with 1,023 children were identified in both Jeddah (25 centers with 628 children) and Makkah (12 centers with 395 children) cities. Out of them, 747 (73\%) were males (499 in Jeddah and 248 in Makkah) and 276 (27\%) were females (129 in Jeddah and 147 in Makkah) with male to female ratio of $3.5: 1$. Their mean age was $8.95 \pm 2.39$ years old and they were diagnosed with ASD, in average, at $3.06 \pm 1.26$ years old. Figure 1 shows the flow of centers and participants included in the study. The estimated prevalence of autistic children attending schools and rehabilitation autistic centers was 2.618 per 1,000 children for Jeddah, 3.68 per 1000 children for Makkah and 2.81 per 1,000 children for Jeddah and Makkah cities.

The number of parents that completed the questionnaire was 205/459 (44.6\%). The low response rate was due to the COVID-19 pandemic that started during the period of our study. ${ }^{16}$

Table 1 shows the characteristic of the participating autistic children. Out of the total sample, 157 (76.6\%) were males; 48 (23.4\%) were females; and 62 (30.2\%) was diagnosed with mild, $106(51.7 \%)$ moderate,, and $37(18 \%)$ severe ASD. There was no significant relationship between the SES and ASD severity (Table 1). The name, locations, and number of responders in the centers are listed in Appendix 1.

Tables 2 and 3 show the distribution of the sample according to ASD severity in children and its relationship to maternal and child factors. There was no significant relationship between those factors and ASD severity.

Table 1 - Characteristics of included participants distributed according to sociodemographic variables and autism severity $(\mathrm{N}=205)$.

\begin{tabular}{|c|c|c|c|c|}
\hline \multirow[t]{2}{*}{ Variable } & \multicolumn{3}{|c|}{ Severity of autism } & \multirow[t]{2}{*}{ Total } \\
\hline & Mild (n=62) & Moderate $(n=106)$ & Severe $(\mathbf{n}=37)$ & \\
\hline \multicolumn{5}{|l|}{ Gender } \\
\hline Male & $52(83.9)$ & $79(74.5)$ & $26(70.3)$ & $157(76.6)$ \\
\hline Female & $10(16.1)$ & $27(25.5)$ & $11(29.7)$ & $48(23.4)$ \\
\hline$P$-value, OR $(95 \% \mathrm{CI})$ & & $0.162,0.56(0.25-1.26)$ & $0.114,0.45(0.17-1.2)$ & \\
\hline \multicolumn{5}{|l|}{ Child order } \\
\hline 1st child & $17(27.4)$ & $30(28.3)$ & $11(29.7)$ & $58(28.3)$ \\
\hline $2 \mathrm{nd}$ or $3 \mathrm{rd}$ & $27(43.5)$ & $32(30.2)$ & $14(37.8)$ & $73(35.6)$ \\
\hline$P$-value, OR (95\% CI) & & $0.320,1.49(0.68-3.26)$ & $0.518,0.73(0.28-1.86)$ & \\
\hline 4 th or more & & $44(41.5)$ & $12(32.4)$ & \\
\hline$P$-value, OR $(95 \% \mathrm{CI})$ & $18(29)$ & $0.427,0.72(0.32-1.62)$ & $0.959,0.97(0.34-2.78)$ & $74(36.1)$ \\
\hline \multicolumn{5}{|l|}{ Paternal education } \\
\hline High school or less & $37(59.7)$ & $50(47.2)$ & $16(43.2)$ & $103(50.2)$ \\
\hline More than high school & $25(40.3)$ & $56(52.8)$ & $21(56.8)$ & $102(49.8)$ \\
\hline$P$-value, OR (95\% CI) & & $0.119,0.60(0.32-1.14)$ & $0.115,0.515(0.23-1.75)$ & \\
\hline \multicolumn{5}{|l|}{ Maternal education } \\
\hline High school or less & $33(53.2)$ & $53(50.0)$ & $19(51.4)$ & $105(51.2)$ \\
\hline More than high school & $29(46.8)$ & $53(50.0)$ & $18(48.6)$ & $100(48.8)$ \\
\hline$P$-value, OR $(95 \% \mathrm{CI})$ & & $0.686,0.88(0.47-1.65)$ & $0.856,0.93(0.4-2.1)$ & \\
\hline \multicolumn{5}{|l|}{ Family income } \\
\hline$<5000$ & $16(25.8)$ & $26(24.5)$ & $11(29.7)$ & $53(25.9)$ \\
\hline $5000-15000$ & $36(58.1)$ & $64(61.4)$ & $25(67.6)$ & $125(61)$ \\
\hline$P$-value, OR (95\% CI) & & $0.53,1.27(0.59-2.72)$ & $0.980,0.99(0.39-2.5)$ & \\
\hline$>15000$ & & $16(15.1)$ & $1(2.7)$ & \\
\hline$P$-value, OR $(95 \% \mathrm{CI})$ & $10(16.1)$ & $0.972,01.06(0.37-2.78)$ & $0.081,6.8(0.77-61.7)$ & $27(13.2)$ \\
\hline \multicolumn{5}{|c|}{ Maternal occupation during pregnancy } \\
\hline Yes & $10(16.1)$ & $15(14.2)$ & $7(18.9)$ & $32(15.6)$ \\
\hline No & $52(83.9)$ & $91(85.8)$ & $30(81.1)$ & $173(84.4)$ \\
\hline$P$-value, OR (95\% CI) & & $0.728,0.86(0.36-2.05)$ & $0.720,1.21(0.42-3.52)$ & \\
\hline
\end{tabular}


Table 2 - Distribution of the participants according to child autism's severity and parental agreement to maternal factors (N=205).

\begin{tabular}{|c|c|c|c|c|}
\hline \multirow[t]{2}{*}{ Variables } & \multicolumn{3}{|c|}{ Severity of autism (\%) } & \multirow[t]{2}{*}{ Total } \\
\hline & Mild (n=62) & Moderate $(n=106)$ & Severe $(n=37)$ & \\
\hline Planned pregnancy & $21(33.9)$ & $37(34.9)$ & $8(21.6)$ & $66(32.2)$ \\
\hline P-value, OR (95\% CI) & & $0.892,1.04(0.54-2.03)$ & $0.198,10.54(0.21-1,38)$ & \\
\hline Fever & $3(4.8)$ & $3(2.8)$ & $1(2.7)$ & $7 \quad(3.4)$ \\
\hline P-value, OR (95\% CI) & & $0.53,0.59(0.12-3.02)$ & $0.606,0.54(0.05-5.4)$ & \\
\hline Hypertension & $1(1.6)$ & $6(5.7)$ & $4(10.8)$ & $11 \quad(5.4)$ \\
\hline P-value, OR (95\% CI) & & $0.231,3.66(0.43-31.13)$ & $0.071,7.39(0.7-68.9)$ & \\
\hline Diabetic & $4(6.5)$ & $6(5.7)$ & $1(2.7)$ & $11 \quad(5.4)$ \\
\hline P-value, OR $(95 \% \mathrm{CI})$ & & $0.899,0.87(0.23-3.21)$ & $0.433,0.41(0.04-3.8)$ & \\
\hline $\begin{array}{l}\text { Maternal medication during } \\
\text { pregnancy }\end{array}$ & $1(1.6)$ & $4(3.8)$ & $1(2.7)$ & $6 \quad(2.9)$ \\
\hline P-value, OR $(95 \% \mathrm{CI})$ & & $0.439,2.39(0.26-21.89)$ & $0.709,1.69(1.03-27.9)$ & \\
\hline $2^{\text {nd }}$ hand smoking & $24(38.7)$ & $35(33)$ & $13(35.1)$ & $72(35.1)$ \\
\hline P-value, OR (95\% CI) & & $0.449,0.78(0.41-1.5)$ & $0.718,0.85(0.37-2)$ & \\
\hline & & odds ratio, CI: confidence & & \\
\hline
\end{tabular}

Table 3 - Distribution of the participants according to child autism's severity and their agreement to child factors $(\mathrm{N}=205)$.

\begin{tabular}{|c|c|c|c|c|}
\hline \multirow[t]{2}{*}{ Variables } & \multicolumn{3}{|c|}{ Severity of autism (\%) } & \multirow[t]{2}{*}{ Total } \\
\hline & Mild (n=62) & Moderate $(n=106)$ & Severe $(n=37)$ & \\
\hline $\begin{array}{l}\text { Associated medical disorder } \\
\quad P \text {-value } \\
\text { OR }(95 \% \mathrm{CI})\end{array}$ & $15(24.2)$ & $\begin{array}{c}16(15.1) \\
0.146 \\
1.8(0.82-3.95)\end{array}$ & $\begin{array}{c}9(24.3) \\
0.990 \\
0.99(0.38-2.57)\end{array}$ & $40(19.5)$ \\
\hline \multicolumn{5}{|c|}{ Type of associated medical disorder } \\
\hline Epilepsy & $3(4.8)$ & $10(9.4)$ & $6(16.2)$ & $19(9)$ \\
\hline P-value, OR (95\% CI) & & $0.289,2.05(0.54-7.75)$ & $0.069,3.8(0.89-16.3)$ & \\
\hline GIT & $17(27.4)$ & $16(15.1)$ & $11(29.7)$ & $44(21.4)$ \\
\hline $\mathrm{P}$ value, OR (95\% CI) & & $0.055,0.47(0.22-1.02)$ & $0.801,1.12(0.45-2.75)$ & \\
\hline Disrupted sleep & $20(32.3)$ & $31(29.2)$ & $13(35.1)$ & $64(31.2)$ \\
\hline P-value, OR (95\% CI) & & $0.681,0.86(0.44-1.71)$ & $0.770,1.13(0.48-2.69)$ & \\
\hline \multicolumn{5}{|c|}{ OR: odds ratio, CI: confidence interval } \\
\hline
\end{tabular}

However, 40 (19.5\%) of the ASD children exhibited some other medical disorder, including epilepsy $(\mathrm{n}=19$, $9.3 \%)$, gastrointestinal disorder $(\mathrm{n}=44,21.5 \%)$, and sleep disorder $(\mathrm{n}=64,31.2 \%)$. Moreover, $72(35.1 \%)$ parents reported that their children were exposed to second-hand smoke.

Table 4 shows the distribution of the sample according to ASD severity in children and its relationship to family history and consanguinity. There was no significant relationship between consanguinity and ASD severity. However, a family history of ASD was reported statistically significantly more often in severe cases of ASD compared to mild cases $(p=0.029$, OR: 3.46 and $95 \%$ CI 1.14 to 10.5 ).
Discussion. The prevalence of ASD is increasing worldwide. In Canada, ASD prevalence in 2015 was reported by the First National Autism Surveillance System to be 15.2 per 1000 among 5- to 17 -year-olds. ${ }^{17}$ Similarly, a Danish study reported the cumulative incidence of ASD in children born in 2008 to be 12 per $1,000 .{ }^{18}$ In the United States (US) $(2012,2014$, and 2016), the Center for Disease Control and Prevention (CDC) reported an ASD prevalence of 14.5, 16.8, and 18.5 per 1,000 8-year-olds children, respectively. ${ }^{1,19}$ Additionally, the National Health Interview Survey (NHIS), a US institute that measures ASD prevalence as reported by parents, found a prevalence of 25 per 1,000 children aged 3 to 17 years from 2015 to $2017 .{ }^{20}$ This 
Table 4 - Distribution of the participants according to child autism's severity and their frequency of family history and consanguinity (N=205).

\begin{tabular}{|c|c|c|c|c|}
\hline \multirow[t]{2}{*}{ Variables } & \multicolumn{3}{|c|}{ Severity of autism (\%) } & \multirow[t]{2}{*}{ Total } \\
\hline & Mild (n=62) & Moderate $(n=106)$ & Severe $(n=37)$ & \\
\hline Consanguinity & $19(30.6)$ & $48(45.3)$ & $13(36.1)$ & $80(39)$ \\
\hline P value, OR (95\% CI) & & $0.063,1.87(0.97-3.63)$ & $0.644,1.23(0.56-2.91)$ & \\
\hline Family history for birth defect & $13(21.9)$ & $35(33.0)$ & $16(43.2)$ & $64(31.2)$ \\
\hline P value, OR (95\% CI) & & $0.098,1.86(0.89-3.87)$ & $0.021^{*}, 2.87(1.18-7.01)$ & \\
\hline Family history of autism & $6(9.7)$ & $16(15.1)$ & $10(27)$ & $32(15.6)$ \\
\hline P value, OR (95\% CI) & & $0.321,1.66(0.61-4.49)$ & $0.029^{*}, 3.46(1.14-10.5)$ & \\
\hline Family history for other medical conditions & $8(12.9)$ & $16(15.1)$ & $5(13.5)$ & $29(14.1)$ \\
\hline P value, OR (95\% CI) & & $0.699,1.2(0.4-2.99)$ & $0.930,1.05(0.32-3.5)$ & \\
\hline \multicolumn{5}{|l|}{ Other medical conditions } \\
\hline $\mathrm{CP}$ & 1 & 1 & 0 & 2 \\
\hline Down syndrome & 1 & 4 & 0 & 5 \\
\hline Delay speech & 3 & 1 & 1 & 5 \\
\hline Mental disability & 2 & 8 & 4 & 14 \\
\hline Growth deficiency & 0 & 2 & 0 & 2 \\
\hline Hearing defect & 1 & 0 & 0 & 1 \\
\hline
\end{tabular}

increase in ASD prevalence suggests that immediate action should be taken toward assessing ASD etiology and risk factors.

In our study, the estimated prevalence of ASD among children aged 6 to 12 years and attending schools or rehabilitation ASD centers in Makkah and Jeddah cities was 2.81 per 1,000 children. This prevalence is supported by previous studies in Saudi Arabia and other Arab countries, ${ }^{7,21}$ that reported an ASD prevalence ranging from 0.14 to 2.9 per 1,000 persons in Oman and the United Arab Emirates (UAE), respectively. In Saudi Arabia, the exact ASD prevalence was not previously established. However, it was estimated to be 1.8 per $1,000^{7,22}$ by studies that were mainly descriptive or single-hospital-based. Therefore, their results could not be generalized to the population. ${ }^{22,23}$

Importantly, given that our study focused on 2 cities, national prevalence of ASD in Saudi Arabia might differ from our results; we predict that it might be higher and closer to the prevalence reported internationally. Further studies should address the broader Saudi Arabia population. As the prevalence of ASD does not seem to be affected by ethnic background, ${ }^{17-19}$ ethnicity was not considered in this study. However, it is worth mentioning that Makkah is a multiethnic city, and it is challenging to predict citizens' ethnicity. In addition, it is one of the most cosmopolitan cities in the world, receiving and uniting Muslims from all over the world on pilgrimage. Geographically, Makkah region is located between 3 main continents (Asia, Africa, and Europe) which makes it unique in its genetic admixture of those populations. This might contribute to the lower prevalence of ASD in this city compared to the international estimates.

In addition, parents of children with mild ASD might have registered their children in a mainstream school, rather than special schools. Moreover, severe ASD with severe associated comorbidities such as epilepsy and intellectual disabilities might be diverted or deprived from educational services. This might explain the lower prevalence of mild (30.2\%) and severe (18\%) ASD compared to moderate $(51.7 \%)$ ASD reported by this study.

Internationally, the prevalence of ASD is consistently higher in males than in females. Christensen et $\mathrm{al}^{24}$ reported ASD prevalence ratios ranged from 2.6 to 5.2 boys per one girl in the US. Studies from South East Asia had confirmed the same finding with a ratio of 2.5:5.1 boys per one girl in South Korea ${ }^{25}$ and 3:1 in Japan. ${ }^{26}$ Further research has reported 2.5-5.1:18 and 3.5:1 male to female ratios. Our research is consistent with the aforementioned reports, yielding a 3.5:1 boy to girl 
ratio. In addition, diagnosis occurred more frequently between 15 to 36 months of age. This early age of diagnosis reflects increased awareness of both families and physicians, which facilitates early recognition and identification of ASD. Moreover, the link between ASD and SES is absent. ${ }^{27}$ Our study confirmed that the prevalence of ASD was nearly equal across SES and parental education level (Table 1).

The increased prevalence of ASD is attributable to different environmental and genetic factors. Different studies have addressed the association of ASD and perinatal risk factors. ${ }^{28}$ Our work did not find a strong association between these variables, which could be related to the small sample size. Meanwhile, the present research found that smoking exposure (during pregnancy and second-hand smoke) was not statistically significantly related to ASD severity, which follows the evidence that smoking is not associated with increased risk of ASD. ${ }^{29}$

In Saudi Arabia, the rate of consanguineous marriage is high, which is expected to generally increase the risk of congenital and genetic disorders in the population. ${ }^{30,31}$ One study investigated 49 individuals with ASD and found that 14 (28.5\%) of them were the product of consanguineous marriages. ${ }^{23}$ Our sample had a higher prevalence, with $39 \%$ of ASD children resulting from consanguineous marriages. However, this prevalence is lower than that reported for Makkah city $(55 \%){ }^{31}$ Although not statistically significant, the higher prevalence of consanguinity in severe and moderate ASD (45.3\% and $36.1 \%$ ) compared to mild ASD (30.6\%) could give a preliminary indication that parental consanguinity might influence the pattern and severity of ASD rather than its prevalence. In addition, ASD pattern and severity could have been affected by the type of consanguineous marriages (namely, first degree compared to second degree). Future research on the association between ASD pattern and severity and types of consanguineous marriages is recommended to either prove or reject this hypothesis. Moreover, 27\% and $43.2 \%$ of children with severe ASD had ASD and birth defect in their family history, respectively, compared to $9.7 \%$ and $22.9 \%$ of those with mild ASD and $15.1 \%$ and $33 \%$ of those with moderate ASD. Although this difference was statistically significant only for family history of ASD, it might support the growing evidence that "idiopathic" ASD is a heritable disorder. ${ }^{32}$ However, this needs to be evaluated on larger sample sizes. Similar to other neuro developmental disorders, ASD is associated with different conditions. These associated disorders vary between studies were where no clear cut; such as epilepsy ( $9 \%$ to $12 \%$ rate), ${ }^{33}$ gastrointestinal issues ( $4.2 \%$ to $97 \%$ rate),${ }^{34}$ and sleep disturbance ( $50 \%$ to $64 \%$ rate)..$^{35}$ In comparison with the international statistics, our sample had a lower rate of epilepsy (9\%), but the rates for gastrointestinal symptoms $(21.4 \%)$ and sleep disturbance $(31.2 \%)$ were comparable with the international reports.

Study limitations. It is possible that some children with ASD were not enrolled in the ASD centers. Analyzing maternal prenatal risk factors using a questionnaire might have result in "recall bias". However, this limitation is difficult to overcome, as ASD diagnoses are not likely until, at the earliest, the age of 14-18 months. ${ }^{36}$ Therefore, a national prospective cohort study is suggested. In addition, it is recommended to assess other risk factors including genetics, epigenetics, and gene-environmental interactions.

In conclusions, our results suggest an estimated prevalence of 2.81 ASD cases per 1,000 children in the Holy city of Makkah and Jeddah together, which is lower than the global prevalence. In addition, there was no statistically significant association between family history of ASD and birth defects and ASD severity; however, a family history of ASD were statistically significantly likely more in severe cases compared to mild cases ( $p=0.029$, OR: 3.46 and $95 \%$ CI 1.14 to 10.5).

Acknowledgment. We would like to acknowledge Editage.com for English language editing.

\section{References}

1. Baio J, Wiggins L, Christensen DL, Maenner MJ, Daniels J, Warren Z, et al. Prevalence of autism spectrum disorder among children aged 8 years-autism and developmental disabilities monitoring network, 11 sites, United States, 2014. MMWR Surveill Summ 2018; 67: 1-23.

2. Wasilewska J, Klukowski M. Gastrointestinal symptoms and autism spectrum disorder: links and risks@ a possible new overlap syndrome. Pediatric Health Med Ther 2015; 6: 153-166.

3. Varcin KJ, Alvares G, Uljarevi M, Whitehouse A. Prenatal maternal stress events and phenotypic outcomes in Autism Spectrum Disorder. Autism Res 2017; 10: 1866-1877.

4. Almandil NB, Alkuroud DN, AbdulAzeez S, AlSulaiman A, Elaissari A, Borgio JF. Environmental and genetic factors in autism spectrum disorders: Special emphasis on data from Arabian studies. Int J Environ Res Public Health 2019; 16: 658.

5. World Health Organization. Autism spectrum disorders 2019 [cited 2020 July 19. Cited 2019 November]. Available from: https://www.who.int/news-room/fact-sheets/detail/autismspectrum-disorders.

6. Adak B, Halder S. Systematic review on prevalence for autism spectrum disorder with respect to gender and socio-economic status. J Ment Disord Treat 2017; 3: 2. 
7. Taha G, Hussein H. Autism Spectrum Disorders in Developing Countries: Lessons from the Arab World; 2014. p. 2509-2531.

8. Ministry of Human Resource and Social Development 2019 [cited 2019 November 10. Cited 2019 November]. Available from: https://hrsd.gov.sa/

9. American Psychiatric Association. Diagnostic and Statistical Manual of Mental Disorders (DSM-5 ${ }^{\circ}$ ). 5th ed. Washington (DC): American Psychiatric Association; 2013.

10. General Authority for Statistics. Demography Survey 2016 Saudi Arabia (KSA): General Authority for Statistics; 2016. Available from: https://www.stats.gov.sa/en/4522.

11. Hansen SN, Schendel D, Francis R, Windham G, Bresnahan M, Levine S, et al. Recurrence Risk of Autism in Siblings and Cousins: A Multi-National, Population-Based Study. J Am Acad Child Adolesc Psychiatry 2019; 58: 866-875.

12. Sabbagh HJ, Alamoudi NM, Abdulhameed FD, Innes NP, Al-Aama JY, Hummaida T, et al. Environmental risk factors in the etiology of nonsyndromic orofacial clefts in the western region of Saudi Arabia. Cleft Palate Craniofac J 2016; 53: 435-443.

13. Gardener H, Spiegelman D, Buka SL. Prenatal risk factors for autism: comprehensive meta-analysis. Br J Psychiatry 2009; 195: 7-14.

14. General Authority for Statistics. Detailed results for Makkah. [Updated 2010. Cited 2020 June]. Available from: https:// www.stats.gov.sa/ar/1417

15. Ministry of Health. Statistical Year Book. [Updated 2010. Cited 2020 June]. Available from: https://www.moh.gov.sa/en/ Ministry/Statistics/book/Pages/default.aspx.

16. Ministry of Health. COVID-19 home page. [Updated 2020. Cited 2020 Dewcember]. Available from: https:// covid19awareness.sa/bn/archives/6036/2020.

17. Ofner M, Coles A, Decou ML, Do M, Bienek A, Snider J, et al. Autism spectrum disorder among children and youth in Canada 2018. Ottawa (CN): Public Health Agency; 2018.

18. Schendel DE, Thorsteinsson E. cumulative incidence of autism into adulthood for birth cohorts in Denmark, 1980-2012. JAMA 2018; 320: 1811-1813.

19. Christensen DL, Braun KVN, Baio J, Bilder D, Charles J, Constantino JN, et al. Prevalence and characteristics of autism spectrum disorder among children aged 8 years-autism and developmental disabilities monitoring network, 11 sites, United States, 2012. MMWR Surveill Summ 2018; 65: 1-23.

20. Kogan MD, Vladutiu CJ, Schieve LA, Ghandour RM, Blumberg SJ, Zablotsky B, et al. The prevalence of parent-reported autism spectrum disorder among US children. Pediatrics 2018; 142: e20174161.

21. Qoronfleh MW, Essa M, Alharahsheh ST, Al-Farsi YM, Al-Adawi S. Autism in the Gulf States: a regional overview. Frontiers In Bioscience, Landmark 2019; 24: 334-346.

22. Alnemary FM, Aldhalaan H, Simón-Cereijido G, Alnemary F. Services for children with autism in the Kingdom of Saudi Arabia. Autism 2017; 21: 592-602.

23. Al-Salehi SM, Al-Hifthy EH, Ghaziuddin M. Autism in Saudi Arabia: presentation, clinical correlates and comorbidity. Transcultural Psychiatry 2009; 46: 340-347.
24. Christensen DL, Maenner MJ, Bilder D, Constantino JN, Daniels J, Durkin MS, et al. Prevalence and characteristics of autism spectrum disorder among children aged 4 years-Early Autism and Developmental Disabilities Monitoring Network, seven sites, United States, 2010, 2012, and 2014. MMWR Surveill Summ 2019; 68: 1-19.

25. Pantelis PC, Kennedy D. Estimation of the prevalence of autism spectrum disorder in South Korea, revisited. Autism 2016; 20 : 517-527.

26. Kurasawa S, Tateyama K, Iwanaga R, Ohtoshi T, Nakatani K, Yokoi $\mathrm{K}$. The age at diagnosis of autism spectrum disorder in children in Japan. Int J Pediatr 2018; 2018: 5374725.

27. DiGuiseppi C, Daniels J, Fallin D, Rosenberg S, Schieve L, Thomas K, et al. Demographic profile of families and children in the Study to Explore Early Development (SEED): Casecontrol study of autism spectrum disorder. Disabil Health J 2016; 9: 544-551.

28. Wang C, Geng H, Liu W, Zhang G. Prenatal, perinatal, and postnatal factors associated with autism. Medicine (Baltimore) 2017; 96: e6696.

29. Rosen BN, Lee B, Lee NL, Yang Y, Burstyn I. Maternal smoking and autism spectrum disorder: A meta-analysis. J Autism Dev Disord 2015; 45: 1689-1698.

30. Sabbagh H, Innes N, Sallout B, Alamoudi N, Hamdan M, Alhamlan N, et al. Birth prevalence of non-syndromic orofacial clefts in Saudi Arabia and the effects of parental consanguinity. Saudi Med J 2015; 36: 1076-1083.

31. Salloum AAA, Mouzan MEE, Herbish AAA, Omer AAA, Qurashi M. Prevalence of selected congenital anomalies in Saudi children: a community-based study. Ann Saudi Med 2015; 35: 107-110.

32. Tick B, Bolton P, Happé F, Rutter M, Rijsdijk F. Heritability of autism spectrum disorders: a meta-analysis of twin studies. $J$ Child Psychol Psychiatry 2016; 57: 585-595.

33. Lukmanji S, Manji S, Kadhim S, Sauro K, Jette N. The cooccurrence of epilepsy and autism: A systematic review. Epilepsy Behav 2019; 98: 238-248.

34. Holingue C, Newill C, Lee L, Pasricha P, Fallin MD. Gastrointestinal symptoms in autism spectrum disorder: A review of the literature on ascertainment and prevalence. Autism Res 2018; 11: 24-36.

35. Heijden KBvd, Stoffelsen R, Popma A, Swaab H. Sleep, chronotype, and sleep hygiene in children with attentiondeficit/hyperactivity disorder, autism spectrum disorder, and controls. Eur Child Adolesc Psychiatry 2018; 27: 99-111.

36. Hyman S, Levy S, Myers SM. Identification, Evaluation, and Management of Children With Autism Spectrum Disorder. Pediatrics 2020; 145: e20193448. 
Prevalence and risk factors of autism ... Sabbagh et al

Appendix 1 - Name of the centers that participated in part 2 of the project.

\begin{tabular}{lccc}
\hline Name of the center & \multicolumn{3}{c}{ n (\%) } \\
& Jeddah City & Makkah City \\
\hline Eithar Center & 5 & $(3.3)$ & 0 \\
Nojoud Center & 1 & $(0.7)$ & 0 \\
Together & 1 & $(0.7)$ & 0 \\
Hope Center & 13 & $(8.6)$ & 0 \\
Alamal Almanshod Center & 5 & $(3.3)$ & 0 \\
Alnakheel Center & $11(7.2)$ & 0 \\
Altanwir Center & 4 & $(2.6)$ & 4 \\
Altawasul Alnajih Center & 1 & $(0.7)$ & $27(57.5)$ \\
(3 centers) & & & \\
Tfaoul and Amal Center & & 0 & $14(29.8)$ \\
Badghish & $9(5.9)$ & 0 \\
The First Autism Center & $30(19.8)$ & $2(4.2)$ \\
I Wii Be (3 centers) & $11(7.3)$ & 0 \\
Joory Center & $11(7.2)$ & 0 \\
Omnyate Center & $21(13.8)$ & 0 \\
Skills Center & $1(0.7)$ & 0 \\
Semsem Center & $31(20.4)$ & $3(6.5)$ \\
Total & $155(100.0)$ & 50 \\
\hline
\end{tabular}

